\title{
OneGeochemistry: Creating a Global \\ Network of Geochemical Data to \\ Support the 17 United Nations \\ Sustainable Development Goals
}

\author{
LESLEY ANNE I WYBORN ${ }^{1}$ AND KERSTIN A LEHNERT ${ }^{2}$ \\ ${ }^{1}$ Australian National University \\ ${ }^{2}$ Columbia University \\ Presenting Author: lesley.wyborn@anu.edu.au
}

The 17 Sustainable Development Goals (SDGs) were set in 2015 by the United Nations (UN) General Assembly to be achieved by the year 2030. Combined, they are the blueprint to achieve a better and more sustainable future and help target the ever increasing global challenges that a sustainable society must solve for the viability of our planet. Geochemistry has the potential to play a fundamental role in all of these SDG: in particular SDG\#6 (Clean Water and Sanitation); SDG\#7 (Affordable and Clean Energy); SDG\#8 (Decent Work and Economic Growth); SDG\#9 (Industry, Innovation and Infrastructure); and SDG\#13 (Climate Action) and SDG\#15 (Life on Land). We do not need separate infrastructures to enable specific geochemical databases to support each SDG - one fundamental, globally distributed interoperable network of geochemistry databases could support all 17 goals.

Over the last century, acquisition and analysis of geochemical data has been pervasive in the Earth, environmental, and planetary sciences. But currently it would be hard to harness this wealth of geochemical data in support of the SDGs. Present-day practices tend to focus on building geochemical databases in either personal, institutional, national, or programmatic silos and there is a noticeable divide in approaches within sectors (research, government, industry, etc). To create a global network of reusable geochemical data the International Geochemistry community needs to come together to define the required, globally-agreed standards and best practices that will enable world-wide interoperability, reuse and open sharing of geochemical data.

We propose the OneGeochemistry initiative to rally all geochemists around the world to come together to help develop the required international standards and define the best practices to enable the creation of a FAIR (Findable, Accessible, Interoperable and Reusable) global network of interoperable distributed geochemical databases. The 17 UN SDGS provide an ambitious call to action for OneGeochemistry. Once the standards are defined and best practices established, existing position located geochemical datasets, regardless of why they were originally collected, could be repurposed to answer new societal challenges that may not have existed at the time the data were collected. 